\title{
DO DIREITO À SAÚDE DA CRIANÇA POR MEIO DOS CUIDADOS À MÃE E A GESTANTE SEGUNDO O ESTATUTO DA CRIANÇA E DO ADOLESCENTE
}

\author{
THE LAW OF CHILD HEALTH THROUGH THE \\ MOTHER TO CARE AND PREGNANT BY \\ STATUTE OF CHILD AND ADOLESCENT
}

Douglas Henrique de Oliveira ${ }^{I}$

\begin{abstract}
RESUMO: Trata-se de trabalho realizado a fim de investigar, sobretudo, o Direito à Saúde da Criança tutelado por meio de medidas cujo público alvo são as mães e gestantes. Para tanto, pretende-se, após um resgate a respeito da noção de Criança enquanto sujeito de Direito, verificar como esta modalidade de Direito à Saúde é tratada pelo Estatuto da Criança e do Adolescente (ECA).
\end{abstract}

Palavra-Chave: Saúde; Criança; Gestante; Maternidade; ECA; Proteção.

ABSTRACT: This is work carried out to investigate, principally, the Right to Health of Children tutored through measures whose the mothers and pregnant women are target audience. Thereunto, it is intended, after redemption of the notion of child as a subject of law, to see how this kind of right to health is dealt with by the Statute of Children and Adolescents (ECA).

Palavra-Chave: Health; Children; Pregnant Women; Motherhood; ECA; Protection.

\section{INTRODUÇÃO}

A elevação da criança e do adolescente à condição de cidadãos e sujeitos de direitos civis, políticos, sociais, culturais e econômicos por meio, sobretudo, do artigo 227 da Constituição Federal, gerou reflexos imensuráveis, que mesmo passados mais de vinte anos da proclamação da Carta Maior, não foram exaustivamente explorados.

A complexidade das relações sociais e o surgimento de novas necessidades para o ser humano com o passar dos anos, fazem com que o conceito e o significado do princípio proteção integral também sofra mutações para abarcar toda a carga valorativa que se renova. Um dos vieses deste princípio é justamente a saúde.

Enquanto política pública social, sabe-se que a saúde, principalmente no que tange à criança e adolescente, foco deste estudo, também ganha novos desdobramentos com o passar dos anos e o surgimento de novas demandas por parte dos cidadãos.

1 Discente do curso de Direito na Universidade Estadual de Londrina. 
Um destes desdobramentos, tema do estudo, diz respeito ao atendimento à gestante e a mãe como forma de tutela ao direito à saúde da criança e do adolescente, tema condensado no artigo oitavo, nono e décimo do Estatuto da Criança e do Adolescente.

Portanto, pretende-se, nas próximas linhas, explorar o conteúdo, bem como suas minúcias, contribuir para o processo de construção da doutrina da proteção integral e disseminar os resultados do estudo com o público que busca esclarecimentos sobre o assunto.

\section{DIREITO DO MENOR E DIREITO DA CRIANÇA E DO ADOLESCENTE: BREVES COMENTÁRIOS HISTÓRICOS}

Toda discussão sobre um tema ligado ao Estatuto da Criança e do Adolescente (ECA) que obedeça a um mínimo de critério lógico haverá, necessariamente, mesmo que de maneira breve, de resgatar um pouco da história da lei, sobretudo no que tange à proteção integral.

Talvez este processo soe um tanto quanto ufanista e repetitivo. Ufanista porque, de certa forma, a produção doutrinária tende a exaltar a lei brasileira como um modelo teórico de excelência a ser atentamente observado pelo mundo. Repetitivo porque muito se argumenta em relação ao Estatuto da Criança e do Adolescente e a proteção integral sem que haja uma apreensão de seu significado e o pior, uma efetiva transformação de seu conteúdo em atitudes concretas.

Entretanto, mesmo diante destas observações, deve-se cautelosamente proceder o resgate do tema, já que a compreensão histórica do ECA, enquanto um microssistema jurídico destinado à tutelar direitos e deveres, o qual surge como antítese de um antigo modelo, é essencial para a discussão de qualquer assunto ligado à área.

Um breve olhar sobre o tratamento legislativo brasileiro dado à criança e ao adolescente necessita ser realizado tendo como ponto de partida a maneira como os pequenos eram vistos pela sociedade de determinada época e local.

Antigamente, apesar da existência da categoria jurídica menor de idade, a qual hipoteticamente asseguraria uma colocação no mundo jurídico, os infantes eram tratados como sujeitos de direito em potencial. João Batista Costa Saraiva (2009, p. 27), analisando a realidade da época, assim descreve a relação pai e filho: "Assim como ao dono do animal incumbe a responsabilidade civil pelo dano por este causado, igual responsabilidade terá aquele que exercer o poder familiar pelos atos do seu filho menor sob sua autoridade e em sua companhia".

Não é difícil se deparar, por exemplo, com fotos de crianças nas décadas iniciais do século XX trajando roupas idênticas as dos adultos, que só diferiam em relação ao tamanho. 
Eram como mini-adultos. Inexistia a consciência da sua importância já em seus primeiros anos de vida.

Em relação ao adolescente, a situação foi um pouco pior, já que há alguns anos atrás não se reconhecia, como hoje, a existência de uma fase de transição entre o ser criança e o ser adulto. Prova disto, é a grande quantidade de pessoas que eram consideradas aptas para o trabalho com seus doze ou quatorze anos, como se observa nas leis de proteção ao trabalho da época.

Além dessa negligência generalizada, as legislações menoristas que antecederam ao Estatuto da Criança e do Adolescente traziam outra característica que merece destaque. A real atenção do legislador era conferida aos menores que poderiam gerar qualquer tipo de risco ou instabilidade à sociedade. Para tanto, eram criadas hipóteses legais, que na prática, acabavam por incluir tão somente os mais pobres.

João Batista Costa Saraiva (2009, p. 37) descreve que na lei de Mello Mattos Decreto 17.943-A de 1927, houve uma distinção entre criança bem nascida daquelas excluídas, estabelecendo uma identificação entre infância socialmente desvalida e infância delinqüente, criando uma nova categoria jurídica: os menores.

Da mesma forma, continua o referido autor, o Código de Menores, lei 6.697 de 1979, seguiu a mesma tendência, ao não dar atenção à criança e ao adolescente como seres possuidores de direitos e por destinar a maior parte do seu texto aos jovens em situação irregular, podendo esta "derivar de sua conduta pessoal (caso de infrações por ele praticadas ou de desvio de conduta) como da família (maus tratos) ou da própria sociedade (abandono) (SARAIVA, 2009, p. 51)".

O estado de abandono e a situação irregular, portanto, era uma moléstia, uma patologia social, independentemente do que haveria levado a tal (seja a própria conduta, seja de circunstância sobre o qual não teve influência) que incomodava a sociedade e necessitava ser afastada, da mesma forma que se varre a poeira para debaixo do tapete.

No entanto, é importante reconhecer o importante passo dado pelos diplomas anteriores ao ECA, que, de sua forma, representaram um caminho progressivo nas questões atinentes à criança e ao adolescente. Neste sentido, mais uma vez João Batista Costa Saraiva (p. 2009, p. 24) expõe ao citar John Stuart Mill:

Toda história do progresso humano foi uma série de transições através das quais costumes e instituições, umas após as outras, foram deixando de ser consideradas necessárias à existência social e passaram para a categoria de injustiças universalmente condenadas. 
Em oposição a Doutrina do Menor sobre a qual até então se fez referências, surgiu o Direito da Criança e do Adolescente. Este, cuja base é a doutrina da proteção integral, ganhou força legal após longos debates na década de 80 que culminaram na promulgação de Constituição da República Federativa do Brasil, a qual, em seu artigo 227, instituiu:

\footnotetext{
É dever da família, da sociedade e do Estado assegurar à criança e ao adolescente, com absoluta prioridade, o direito à vida, à saúde, à alimentação, à educação, ao lazer, à profissionalização, à cultura, à dignidade, ao respeito, à liberdade e à convivência familiar e comunitária, além de colocá-los a salvo de toda forma de negligência, discriminação, exploração, violência, crueldade e opressão.
}

Esta nova situação consolidou o mencionado princípio da proteção integral, um núcleo jurídico essencial que engloba um conjunto de direitos sem os quais o desenvolvimento da criança e do adolescente ficaria prejudicado. São direitos necessários e já garantidos a todos por meio de leis nacionais e internacionais. Mesmo assim, foram expressamente estendidos aos infantes, como a vida, o trabalho, a educação, o lazer e a saúde, sendo esta última, objeto a ser tratado no próximo tópico.

\section{O DIREITO À SAÚDE DA CRIANÇA E DO ADOLESCENTE}

O capítulo I do título II do ECA foi um marco nesta transição de tratamento dado a criança e ao adolescente. Pela primeira vez em uma legislação específica infraconstitucional sobre os infantes, há dispositivos expressamente regulamentando o direito à vida e a saúde. Mais do que isto, a lei foi além ao abordar a questão da saúde principalmente sob o foco preventivo, na linha dos ditames constitucionais.

Em um breve olhar para o passado, verifica-se que o Decreto 17.943-A de 1927, popularmente conhecido como Código de Mello Mattos, e a lei 6.697 de 1979, denominada de Código de Menores, diplomas que antecederam o ECA, também mencionaram a questão da saúde em seus dispositivos.

No entanto, em ambos, é possível identificar o caráter secundário e predominantemente recuperativo atribuído à saúde. Secundário porque a terminologia saúde só foi utilizada pelos legisladores como uma nomenclatura comum para conferir coesão a outro tema. Assim, tem-se, por exemplo, o capítulo IV da Lei de Mello Mattos que aborda os menores abandonados: 
Art. 26 Consideram-se abandonados os menores de 18 annos:

[...] c) empregados em occupações prohibidas ou manifestamente contrarias á moral e aos bons costumes, ou que lhes ponham em risco a vida ou a saude; (grifo nosso)

Em sentido similar, institui o Código de Menores:

Art. $2^{\circ}$ Para os efeitos deste Código, considera-se em situação irregular o menor:

I- Privado de condições essenciais à sua subsistência, saúde e instrução obrigatória $[\ldots][$ sic] (grifo nosso).

Note-se, nestes exemplos, que a palavra saúde aparece tão somente como um termo acessório para que se possa compreender o que venha a ser um menor abandonado ou em situação irregular.

Já no que diz respeito ao sentido curativo, houve esta constatação devido à menção da saúde, nas leis anteriores, quando o problema já existia ou como meio auxiliar para recuperar os chamados menores que se encontravam em situação de risco. Mais uma vez, tem-se um dispositivo do Código de Mello Mattos, que dispõe das medidas aplicáveis aos menores abandonados:

Art. $9^{\circ}$ A autoridade publica póde impedir de ser abrigada, e si já o estiver póde ordenar a apprehensão e remoção, a creança nas condições deste capitulo:

a) em alguma casa cujo numero de habitantes fôr excessivo, ou que fôr perigosa ou anti-hygienica; [...]

Art. 10. Si, em consequencia de infracção de dispositivo deste capitulo ou da falta de cuidado da parte da nutriz ou guarda, resultou damno á, saude, ou vida da creança, será applicada a pena do art. 306 ou 297 do Codigo Penal (grifo nosso) [sic].

Neste sentido, ainda é possível elencar no Código de Menores:

Art. 42. São medidas aplicáveis aos pais ou responsável:

[...] II - obrigação de submeter o menor a tratamento em clínica, centro de orientação infanto-juvenil, ou outro estabelecimento especializado determinado pela autoridade judiciária [...] (grifo nosso) [sic];

Entretanto, como já mencionado, a queda do regime militar e o surgimento de uma nova realidade social no Brasil na década de oitenta, propiciou o movimento por uma nova Ordem Constitucional, que se estabeleceu a partir de Outubro de 1988. 
Nesta, conforme ensinamento de José Afonso da Silva (2006, p. 831), a saúde passa a ser concebida como um direito de todos e dever do Estado, passando a ter como princípios norteadores "a universalidade e a igualdade de acesso às ações e serviços que a promovem, protegem e recuperam".

Ademais, a própria Constituição em seu artigo 227 confere tratamento específico à criança e ao adolescente ao firmar um amplo compromisso com os múltiplos direitos que compõe a proteção integral e, como não poderia deixar de ser, com a saúde:

Art. $227, \S 1^{\circ}$ - O Estado promoverá programas de assistência integral à saúde da criança e do adolescente, admitida a participação de entidades não governamentais [...] (grifo nosso).

O Estado da Criança e do Adolescente, lei 8.069 de 1990, seguindo a orientação da Constituição Federal, trouxe em seus artigos um tratamento amplo à saúde da criança e do adolescente em seu Título II, Capítulo I, rompendo com o modelo adotado nas leis anteriormente estudadas, como se demonstrará em momento oportuno.

No entanto, nem sempre uma alteração legislativa produz mudanças na sociedade, principalmente quando sua efetivação depende de políticas públicas. Da mesma forma, a adoção de uma nova doutrina, no que diz respeito à criança e ao adolescente, ou a elevação do direito à saúde como dever do Estado, nem sempre representará concretude.

O Direito não é mera declaração de intenções. Ele emana da sociedade, mas também é um grande elemento condicionante dessa, assim como as forças econômicas, culturais e políticas. O Direito atua fixando princípios e normas a serem observados coercitivamente pela população. Justamente neste ponto é que se verifica a importância destas mudanças legais.

O que trará, então, efetividade aos institutos jurídicos elencados na Constituição Federal e no ECA? Nos dizeres de Rudolf Von Ihering (2001, p. 27), é a luta pelo Direito.

É a conscientização e a vontade de orientar sua conduta conforme os preceitos legais a grande garantia de que o Direito será cumprido. O Direito não é puramente científico. É força viva, labor, contribuição e luta por um objetivo maior: a paz.

A enunciação de direitos propicia o surgimento de um cenário em que passa a ser possível a exigência de comportamentos positivos dos sujeitos responsáveis pela tutela dos Direitos da Criança e do Adolescente.

É com base nestes pensamentos, a da construção do Direito, mas sempre atento para não cair no puro dogmatismo, que se realiza este trabalho que, tendo abordado questões gerais 
em relação à saúde e sua colocação em face da Constituição de 1988, passa a abordar o Direito à saúde tutelado pelo ECA em vias indiretas por meio da proteção à gestante e a maternidade, para buscar sua concretização por meio da disseminação do conhecimento.

\section{O ESTATUTO DA CRIANÇA E DO ADOLESCENTE E O DIREITO À SAÚDE POR MEIO DA PROTEÇÃO À GESTANTE E MATERNIDADE.}

Dentre os dispositivos que conferem tratamento à saúde da criança e do adolescente dentro do ECA, urge destacar três cujo diferencial reside no fato de propor um conjunto de ações destinados, em primeiro momento, à gestante ou a mãe, para, indiretamente, tutelar os infantes. São eles os artigos $8^{\circ}, 9^{\circ}$ e $10^{\circ}$ da lei 8.069/90.

Assim, o Estatuto da Criança e do Adolescente busca adequar a realidade brasileira a tratados internacionais que, embora assinados pelo Brasil, foram, durante muito tempo, negligenciados, como se verifica no próprio princípio quarto da Declaração de Direitos da Criança da ONU de 1959:

A criança gozará os benefícios da previdência social. Terá direito a crescer e criar-se com saúde; para isto, tanto à criança como à mãe, serão proporcionados cuidados e proteção especial, inclusive adequados cuidados pré e pós-natais. A criança terá direito a alimentação, recreação e assistência médica adequadas. (grifo nosso).

Posto isto, passa-se a estudar de modo esmiuçado os artigos do ECA, procurando investigar as devidas terminologias a fim de que eventuais dúvidas possam ser ao menos minimizadas.

\section{Artigo oitavo: a gestante e o atendimento junto ao sistema único de saúde}

Na esteira do que prega o artigo 201, II, da Constituição Federal, ao determinar que a previdência social deverá proteger a maternidade, especialmente à gestante, o artigo $8^{\circ}$ do ECA estatui o seguinte:

É assegurado à gestante, através do Sistema Único de Saúde, o atendimento pré e perinatal.

$\S 1^{\circ}$ A gestante será encaminhada aos diferentes níveis de atendimento, segundo critérios médicos específicos, obedecendo-se aos princípios de regionalização e hierar- 
quização do Sistema.

$\S 2^{\circ}$ A parturiente será atendida preferencialmente pelo mesmo médico que a acompanhou na fase pré-natal.

$\S 3^{\circ}$ Incumbe ao poder público propiciar apoio alimentar à gestante e à nutriz que dele necessitem.

$\S 4^{\circ}$ Incumbe ao poder público proporcionar assistência psicológica à gestante e à mãe, no período pré e pós-natal, inclusive como forma de prevenir ou minorar as consequências do estado puerperal.

$\S 5^{\circ} \mathrm{A}$ assistência referida no $\S 4^{\circ}$ deste artigo deverá ser também prestada a gestantes ou mães que manifestem interesse em entregar seus filhos para adoção.

Trata-se o caso de dispositivo que visa atribuir a proteção da gestante ao Sistema Único de Saúde (SUS) e, consequêntemente, ao Poder Público, com o objetivo de prevenir eventuais problemas que possam surgir no período que circunda o parto.

OSUS consisteemumnovomodelodeatendimentoàsaúdeinspiradonanovaOrdemConstitucionalde 1988 ecriadopelalei 8.080/90. Buscaesseproporcionaroatendimentopúblicodasaúde pautando-senos princípios da universalidade (atendimento a todos indistintamente), integralidade (de todas as necessidades preventivas e curativas existentes) e equidade (igualdade de oportunidade para a utilização dos serviços), conforme se extrai dos artigos 196 a 200 da Constituição Federal.

De acordo com uma breve verificação a ser realizada no caput do artigo em estudo, cabe ao SUS o atendimento à gestante. Mas em que consiste a terminologia gestante? Quando se inicia e termina o período de gestação?

Há certa controvérsia a respeito do início da gestação, haja vista a existência de posicionamentos distintos sobre o próprio início da vida. Entretanto, distanciando-se da discussão que não é foco deste estudo, sabe-se que a gestação "se refere ao estado resultante da fecundação de um óvulo pelo espermatozóide, envolvendo também o subseqüente desenvolvimento, no útero, do feto que foi gerado pela fecundação, encerrando-se na expulsão, chamada de "parto" ou "nascimento" (GRAVIDEZ, 2010).

Da mesma forma, nos seres humanos, a gravidez também se refere ao estado resultante da fecundação de um óvulo pelo espermatozóide, envolvendo o desenvolvimento do feto gerado no útero, que dura nove meses, até seu nascimento.

Portanto, é esta mulher em período gestacional o público alvo das ações que emanam do dispositivo em análise. Ações estas que envolvem atendimentos no período pré e perinatal. Eis aqui outros dois elementos a serem esclarecidos.

O período pré-natal vai do momento da fecundação ao longo do tempo da gravidez (quarenta semanas) e o período perinatal do momento do trabalho de parto até as primeiras 
quarenta e oito horas. Sobre esse período e o primeiro mês de vida, comenta Evelyn Eisenstein (CURY, 2006, p. 58):

São considerados, além de críticos, períodos vulneráveis. Idealmente, os cuidados de saúde devem ser abrangentes e com um enfoque multidisciplinar, integrando a gestante, o seu concepto, a sua família, inclusive o pai responsável pela gestação, em todas as etapas da gravidez, do parto, e até o primeiro ano de vida do recém-nato.

Ainda dissertando sobre esses cuidados, continua a referida autora:

O estado geral de nutrição, higiene e saúde da mãe, além dos cuidados e suporte social recebidos durante a gestação e a lactação (período de amamentação), são os elementos básicos que constituem o que denominamos de "padrão de vida", ou, simplesmente, o "bem-estar" de indivíduos, famílias e sociedades. O melhoramento das condições de vida, entre as gerações, só será possível quando forem assegurados os direitos da gestante e da nutriz, perante o sistema de saúde e a sociedade, em todos os seus segmentos (CURY, 2006, p. 59).

Essa etapa da vida é tão importante que o legislador houve por bem assegurar o atendimento das presas e internadas em estabelecimentos prisionais, conforme redação do artigo 14, $\S 3^{\circ}$ da Lei de Execução Penal, que assim dispõe: "Será assegurado acompanhamento médico à mulher, principalmente no pré-natal e no pós-parto, extensivo ao recém-nascido".

O parágrafo primeiro do artigo oitavo determina o encaminhamento da gestante aos diferentes níveis de atendimento, segundo critérios médicos específicos, demonstrando assim, clara alusão ao princípio da integralidade do atendimento ao SUS, já que este deve buscar encaminhamentos para todas as necessidades da gestante.

O mencionado dispositivo ainda institui que o encaminhamento da gestante obedecerá a dois princípios de organização do Sistema Único de Saúde: a Regionalização e a Hierarquização.

Regionalização consiste na aplicação do princípio da territorialidade, com foco na busca de uma lógica sistêmica, evitando atomização dos sistemas locais de saúde, por meio da definição de uma área geográfica e da população a ser atendida (MINISTÉRIO DA SAÚDE. Disponível em: www.geosc.ufsc.br/babcsus.pdf).

Porhierarquização entende-se anecessidade de organização do Sistema emníveis de complexidadetecnológicacrescente. Nestesentido, esclareceaCartilhadoMinistériodaSaúdede 1990: 
O acesso da população à rede deve se dar através dos serviços de nível primário de atenção que devem estar qualificados para atender e resolver os principais problemas que demandam os serviços de saúde. Os demais, deverão ser referenciados para os serviços de maior complexidade tecnológica. (MINISTÉRIO DA SAÚDE. Disponível em: www.geosc.ufsc.br/babcsus.pdf).

Sabe-se que os mencionados princípios são visualizadosnaprática, não apenas porquestão deescolhapolítica, mastambém por existirumanecessidade organizacional eeconômica, haja vista a impossibilidade de se manter poucos centros de atendimentos e alto padrão tecnológico em todos.

O parágrafo segundo do artigo oitavo menciona o atendimento da gestante pelo mesmo médico em caráter preferencial. Percebe-se aqui a intenção de se criar um vínculo entre o paciente e o médico, com o objetivo de buscar a excelência no diagnóstico. Entretanto, o próprio parágrafo faz uma ressalva ao expor o termo preferencialmente, o que não denota a existência de obrigatoriedade. Ademais, sabe-se que a concretização deste dispositivo não se verifica todas as localidades, haja vista as dificuldades estruturais que a própria rede de saúde encontra para organizar o atendimento.

No que tange ao parágrafo terceiro, verifica-se a utilização do termo nutriz, que diz respeito à mulher que amamenta ou nutre a criança. O público a ser atendido é de gestantes $\mathrm{e}$ nutrizes, que devem receber apoio alimentar, já que a falta de uma alimentação saudável pode prejudicar a produção de leite e, consequentemente, a nutrição da criança.

Há estudos que apontam que, durante a amamentação, a mulher, que geralmente consome duas mil calorias por dia, deve passar a consumir duas mil e quinhentas calorias, justamente por conta da produção do leite. Além disso, sua alimentação deve ser rica em fontes energéticas, como o carboidrato, a proteína e a gordura (STELLA. Disponível em http://www. minhavida.com.br/conteudo/1594-Alimentacao-certa-para-a-mulher-que-amamenta.htm).

Hoje, sabe-se da existência de programas governamentais de cunho social os quais visam atender este tipo de demanda apregoada no parágrafo estudado. Para tanto, as próprias unidades e centros de atendimento à saúde, em parceria com os Centros de Referência de Assistência Social, devem detectar estas necessidades e realizar os encaminhamentos.

Os parágrafos quarto e quinto foram incluídos no artigo oitavo do ECA por meio da reforma legislativa promovida pela lei 12.010 de 2009, que, de modo genérico, estabeleceu diversos dispositivos a cerca da adoção no Brasil.

O parágrafo quarto dispõe acerca da assistência psicológica à gestante e a mãe, no período pré e pós-natal, como forma de prevenir ou minorar as conseqüências do estado puerperal. Dois pontos devem ser destacados em relação a este dispositivo. 
Primeiro, o reconhecimento da necessidade da assistência psicológica. O ser humano é multifacetário, ou seja, possui múltiplas necessidades nas diversas áreas imagináveis. Assim, é fácil conceber que uma eventual assistência a um indivíduo, para captar sua integralidade, deverá sobrepor meros cuidados físicos e abranger outras áreas. É justamente neste sentido que surge a assistência psicológica à mãe e a gestante, como uma forma de prestar um atendimento integral que satisfaça todas as suas necessidades.

O segundo ponto diz respeito ao objetivo de todos estes cuidados. Trata-se de minorar ou prevenir as conseqüências do estado puerperal, entendido como período variável, de evolução diferente de mulher para mulher, onde, concomitante ao efetivo exercício da maternidade, a mulher experimenta profundas modificações genitais, gerais e psíquicas, com gradativo retorno ao período não gravídico (FERREIRA. Disponível em: http://www.aguaviva.mus.br/enfermateca/Artigos/Puerperio.htm).

Não obstante se tratar de uma alteração recente, sabe-se da existência de locais em que este tipo de acompanhamento já é disponibilizado para gestantes. Da mesma forma, é possível afirmar a existências de muitas realidades diferentes dentro de nosso país, motivo pela qual a nova determinação legal pode fomentar esta política pública a fim de estender o atendimento para os locais que necessitam.

O parágrafo quinto estende o tratamento psicológico às mães e gestantes que manifestem interesse em entregar seus filhos à adoção. Trata-se de evolução na legislação pátria, que passa dar atenção a esta mulher que, até então, além de não receber cuidados, era rotulada.

Por fim, frisa-se, quanto a este ponto, que as grávidas que quiserem doar seus filhos devem ser encaminhadas à Justiça da Infância e da Juventude pelos profissionais que souberem do desejo. O médico, enfermeiro ou dirigente de estabelecimento de atenção à saúde de gestante que deixar de efetuar imediato encaminhamento à autoridade judiciária poderá ser penalizado, conforme artigo 258-B do Estatuto da Criança e do Adolescente.

\section{Artigo nono: a proteção integral e o aleitamento materno}

O dispositivo agora a ser estudado atribui a diferentes sujeitos a obrigação de zelar pela saúde da criança a ser garantida por meio do aleitamento materno ou amamentação:

Art. $9^{\circ} \mathrm{O}$ poder público, as instituições e os empregadores propiciarão condições adequadas ao aleitamento materno, inclusive aos filhos de mães submetidas a medida privativa de liberdade. 
O aleitamento materno é uma fundamental etapa do desenvolvimento do ser humano, justamente por se tratar de um período de vulnerabilidade do indivíduo e de aproximação com sua família e com o mundo. Sua importância reside em aspectos biológicos e psicológicos.

Em relação aos biológicos, conforme assevera José Heitor dos Santos (Disponível em http://www.pjpp.sp.gov.br/2004/artigos/10.pdf), o leite materno contém uma substância que aparece logo após o parto, denominada colostro. Esta possui elementos que protegem o bebê contra a maioria das doenças da primeira infância, sendo, portanto, importante que o recémnascido ingira colostro, mesmo que a mulher decida não amamentar por muito tempo.

Por outro lado, continua o autor citando Antônio Chaves (SANTOS. Disponível em http://www.pjpp.sp.gov.br/2004/artigos/10.pdf), existem aspectos espirituais que envolvem tal prática. "O aconchego do ato de mamar cria entre a mãe e filho um profundo clima de identificação e marca, para sempre, a personalidade da criança, preparando-a para saber transmitir e receber amor".

A relevância do tema é tamanha que a própria Convenção dos Direitos da Criança de 1989, ratificada pelo Brasil, instituiu em seu artigo 24 a determinação para que os Estados Partes adotem medidas apropriadas com vistas a assegurar que todos os setores da sociedade, e em especial os pais e as crianças, conheçam os princípios básicos de saúde e nutrição das crianças, bem como as vantagens da amamentação.

$\mathrm{O}$ artigo $9^{\circ}$ do ECA menciona que os empregadores devem propiciar condições adequadas para o aleitamento materno. No que tange ao aspecto trabalhista, a Consolidação das Leis Trabalhistas (CLT) traz ao longo de seu texto alguns dispositivos que visam tutelar o trabalho da mulher.

O ponto que nos interessa nessas questões diz respeito aos dispositivos que tutelam a amamentação. Conforme redação do artigo 396 da CLT, para amamentar o próprio filho, até que este complete seis meses de idade, a mulher terá direito, durante a jornada de trabalho, a dois descansos especiais, de meia hora cada um e, quando o exigir a saúde do filho, o período de seis meses poderá ser dilatado, a critério da autoridade competente.

A CLT ainda dispõe em seu artigo $389, \S 1^{\circ}$, que os estabelecimentos em que trabalharem pelo menos trinta mulheres com mais de dezesseis anos de idade terão local apropriado onde seja permitido às empregadas guardar sob vigilância e assistência os seus filhos no período da amamentação. $\mathrm{O} \S 2^{\circ}$ ressalva que esta exigência poderá ser suprida por meio de creches distritais mantidas pelas próprias empresas, em regime comunitário, ou a cargo do SESI, do SESC, da LBA ou de entidades sindicais. 
Por fim, o artigo 400 da CLT institui que os locais destinados à guarda dos filhos das operárias durante o período da amamentação deverão possuir, no mínimo, um berçário, uma saleta de amamentação, uma cozinha dietética e uma instalação sanitária.

Outro ponto de grande relevância na lei diz respeito à amamentação para as mulheres submetidas a medidas privativas de liberdade. Quanto a isto, deve-se ter em mente não as penas cumpridas em regime fechado, mas também as medidas socioeducativas de internação e semiliberdade, aplicadas a adolescentes.

Em relação ao tema em foco, tem-se como ponto de partida a regra disposta no artigo $5^{\circ}, \mathrm{L}$ da Constituição Federal, que garante às presidiárias condições para que possam permanecer com seus filhos durante o período de amamentação.

A lei 11.942 de 2009 promoveu alterações na Lei de Execução Penal regulamentando este direito. Em seu artigo $83, \S 2^{\circ}$, a lei determina que os estabelecimentos penais destinados a mulheres serão dotados de berçário, onde as condenadas possam cuidar de seus filhos, inclusive amamentá-los, no mínimo, até seis meses de idade.

A reforma legislativa foi além da questão da amamentação e trouxe, em seu artigo 89, a obrigação de que as penitenciárias de mulheres sejam dotadas de creche para abrigar crianças maiores de seis meses e menores de sete anos, com a finalidade de assistir a criança desamparada cuja responsável estiver presa.

Fixa, por fim, requisitos básicos para a creche, qual seja, atendimento por pessoal qualificado, de acordo com as diretrizes adotadas pela legislação educacional e em unidades autônomas e horário de funcionamento que garanta a melhor assistência à criança e à sua responsável.

\section{Artigo décimo: medidas legais após nascimento da criança}

O presente tópico visa estudar as medidas a serem observadas por hospitais e outros centros de atendimento à saúde da gestante, sejam públicos ou particulares, nos momentos que sucedem o nascimento da criança. Tratam-se de determinações sem precedência nas legislações anteriores e que proporcionam reflexos para toda a vida do indivíduo, conforme se analisará.

Art. 10. Os hospitais e demais estabelecimentos de atenção à saúde de gestantes, públicos e particulares, são obrigados a:

I - manter registro das atividades desenvolvidas, através de prontuários individuais, pelo prazo de dezoito anos; 
II - identificar o recém-nascido mediante o registro de sua impressão plantar e digital e da impressão digital da mãe, sem prejuízo de outras formas normatizadas pela autoridade administrativa competente;

III - proceder a exames visando ao diagnóstico e terapêutica de anormalidades no metabolismo do recém-nascido, bem como prestar orientação aos pais;

IV - fornecer declaração de nascimento onde constem necessariamente as intercorrências do parto e do desenvolvimento do neonato;

$\mathrm{V}$ - manter alojamento conjunto, possibilitando ao neonato a permanência junto à mãe.

No inciso primeiro deste artigo, há determinação de registrar todas as atividades desenvolvidas, tomando-se como termo inicial desta obrigação o nascimento da criança e termo final a maioridade civil. Apesar de não ser a redação da lei, é relevante que os prontuários constem inclusive informações sobre o pré-natal da gestante, haja vista que o objetivo maior é a proteção da saúde da criança que já se encontra em desenvolvimento.

De modo objetivo, o dispositivo é uma grande ferramenta para fins de acompanhamento médico, pois as informações podem contribuir e muito para diagnósticos posteriores. Ademais, o grande lapso de tempo dos registros possibilita que qualquer dúvida a respeito da mãe ou do filho possa ser sanada.

Sabe-se que muitos hospitais e estabelecimentos destinados ao atendimento à saúde mantêm este tipo de registro. Por outro lado, verifica-se em alguns locais a ausência de um banco de dados que centralize as informações ou que faça ao menos indicações a respeito do estabelecimento responsável por determinado registro, o que pode gerar dificuldades para a busca das informações.

Os registros mostram-se úteis até para outros dispositivos do ECA, como no caso do artigo $102, \S 1^{\circ}$, que dispõe que verificada a inexistência de registro civil, o assento de nascimento da criança ou adolescente será feito à vista dos elementos disponíveis, como, em caso, os registros em prontuário de hospitais.

O ponto de maior atenção reside na maneira como estes registros serão organizados. Não há regulamentação no ECA sobre a forma em que esses prontuários devem ser mantidos, se em forma de arquivos, processos ou até mesmo com a utilização da informática e seus respectivos discos de armazenamento, motivo pelo qual se infere que o assunto deve ser regulado pelos órgãos competentes para evitar a falta de padronização.

Quanto ao conteúdo, há de se perceber que o registro deve ser o mais abrangente possível, a ponto de possuir dados que possam auxiliar terceiros nas mais diversas finalidades. Desta 
forma, os prontuários devem conter informações a respeito da identificação da criança e da mãe, com a indicação de como, quando e onde foi realizada; dos exames visando o diagnóstico e terapêutica de anormalidades no metabolismo do recém-nascido; outros exames relativos ao período de gestação, como ecografias uterinas, biópsias, ecocardiograma fetal, etc; do fornecimento da declaração, quando realizado, onde e quem a pegou, com o respectivo visto; sobre o alojamento ou local em que a mães e sua criança foram mantidas, dentre outros.

Melhor mesmo seria se houvesse uma padronização dos requisitos e modelos a serem utilizados, conforme atesta a doutrina (CURY, 2006, p. 64):

Seria extremamente útil para os estudos futuros se esta medida viesse acompanhada dos dados mínimos, básicos, que necessitam ser arquivados. Não temos, hoje, no Brasil, uma ficha de identificação neonatal padronizada e em uso nas instituições que atendem recém-nascidos.

O não atendimento das providências elencadas neste inciso acarreta a configuração de crime do artigo 228 do próprio ECA, o que evidencia definitivamente a relevância do tema. Assim capitula a primeira parte do referido artigo:

Deixar o encarregado de serviço ou o dirigente de estabelecimento de saúde de gestante de manter registro das atividades desenvolvidas, na forma e prazo referidos no art. 10

Pena - detenção de seis meses a dois anos.

Parágrafo único. Se o crime é culposo:

Pena - detenção de dois a seis meses, ou multa.

A norma responsabiliza o encarregado do serviço ou o gerente do hospital, vislumbrando-se uma hipótese de concurso de pessoas, ou seja, quando mais de uma pessoa pode ser processada pelo presente crime simultaneamente.

Encarregado de serviço, segundo se infere do próprio texto do ECA é a pessoa que tem a incumbência através de prontuários individuais e pelo prazo de dezoito anos, de manter registros das atividades desenvolvidas nos estabelecimentos de atenção à saúde de gestantes e de fornecer à parturiente declaração de nascimento onde constem as intercorrências do parto e do desenvolvimento do neonato.

Não obstante a relevância do dispositivo, a doutrina penal destaca a danosa indeterminação do dispositivo, já que nem sempre é possível identificar o responsável pelo registro e a lei 
não menciona qual diretor será responsabilizado, o diretor do presente ou o da época em que o registro deveria ser feito. Para Alberto Silva Franco (2001, p. 527), “[...] a figura típica do 228 constitui, sem dúvida, um tipo penal inócuo e inconseqüente, quase uma piada de mau gosto".

Ressalta-se que é possível que haja caracterização do crime por culpa, ou seja, quando não houve a intenção de deixar de fazer o registro. Por isso a necessidade de extrema cautela por parte dos hospitais que prestam atendimento à criança e ao adolescente.

Por fim, no que tange ao acesso a esses dados, a doutrina afirma que é cabível habeas data no caso de negativa das informações, a princípio pela via administrativa e posteriormente junto as vias judiciais (CURY, 2006, p. 63).

O inciso segundo do artigo 10 do ECA determina a identificação do recém-nascido mediante o registro de sua impressão plantar e digital e da impressão digital da mãe, como uma tentativa de tentar evitar a troca de crianças, que tanto chama a atenção diante dos casos revelados pelo Brasil.

Entretanto, a doutrina alerta para alguns pontos da medida. "A impressão plantar do recém-nascido não possibilita identificação adequada no caso de dúvida. Especialistas na área são unânimes em afirmar que, além do risco de intoxicação, a impressão plantar não é uma medida de validade na prática diária”. (CURY, p. 64).

Realmente a prática tem mostrado que dificuldades estruturais ainda fazem com que outros tipos de sistema de identificação sejam adotados. A famigerada pulseira, não obstante a insegurança que pode trazer, ainda é muito utilizada em hospitais brasileiros e vem sendo até alvo de tentativas de regularizá-la.

O projeto de lei 1067/07, que se encontra atualmente na Comissão de Seguridade Social e Família, tenta obrigar hospitais e maternidades públicas a colocar, no recém-nascido e na mãe, pulseiras com gravação numérica inviolável, lacrada e indelével. (Disponível em: http:// www.camara.gov.br/sileg/Prop_Detalhe.asp?id=351542)

De acordo com a proposta, a pulseira deverá ser colocada imediatamente após o nascimento da criança, na sala e na presença de toda a equipe que tenha realizado o parto. Além disso, as pulseiras somente poderão ser retiradas após a saída da mãe e do filho do hospital.

Assim como o inciso primeiro, o dispositivo ora estudado também é tutelado por norma de cunho penal, qual seja, a segunda parte do artigo 229 do próprio Estatuto da Criança e do Adolescente: 
Deixar o médico, enfermeiro ou dirigente de estabelecimento de atenção à saúde de gestante de identificar corretamente o neonato e a parturiente, por ocasião do parto.

Pena - detenção de seis meses a dois anos.

Parágrafo único. Se o crime é culposo:

Pena - detenção de dois a seis meses, ou multa.

Assim como no dispositivo anterior, o artigo 229 busca tutelar a realização das providências do artigo 10 do ECA como forma de garantir o direito à saúde da criança e os interesses de sua mãe, motivo pelo qual maiores considerações tornam-se dispensáveis.

O inciso terceiro determina a realização de exames visando ao diagnóstico e terapêutica de anormalidades no metabolismo do recém-nascido, bem como a prestação de orientação aos pais.

A respeito das anormalidades no metabolismo, comenta a doutrina:

[...] Erros inatos de metabolismo são alterações da síntese de moléculas de proteínas, que se transmitem aos descentes, e são causadas por mutações capazes de modificar a condição genética do indivíduo, de modo a produzir alterações funcionais. As manifestações clínicas são as mais diversas, sendo muito importante a deficiência mental. A fenilcetonúria caracteriza-se pelo distúrbio provocado pela falta de atividade das enzimas fenilalanina hidroxilase e/ou diipropteridina redutase, com o conseqüente acúmulo da finilalanina e de seus metabolismos, causando lesão irreparável ao sistema central em desenvolvimento, a menos que a patologia seja diagnosticada e tratada dentro das primeiras três a seis semanas de vida. O hipotireoidismo congênito consistem em distúrbio metabólico ligado a erro na síntese hormonal, que se caracteriza pela ausência ou deficiência parcial do hormônio tireoidiano (T4). Níveis diminuídos de T4 acarretam um comprometimento no crescimento de todo o organismo e, em especial, no desenvolvimento cerebral. O diagnóstico da fenilcetonúria (PKU) e do hipotireoidismo (T4) deve se elaborado precocemente, nos primeiros dias de vida. (CURY, 2002, p. 26).

Assim como no caso anterior, há tutela de norma de caráter penal sobre o conteúdo deste artigo, conforme se verifica no artigo 229 do próprio ECA:

Deixar o médico, enfermeiro ou dirigente de estabelecimento de atenção à saúde de gestante de $[. .$.$] proceder aos exames referidos no art. 10$ desta lei.

Pena - detenção de seis meses a dois anos.

Parágrafo único. Se o crime é culposo:

Pena - detenção de dois a seis meses, ou multa. 
Em relação a este, cabe-se apenas retomar as considerações tecidas em relação norma incriminadora relativa ao inciso II do artigo décimo.

O inciso quarto determina o fornecimento de declaração de nascimento onde constem as intercorrências do parto e do desenvolvimento do neonato.

O ECA não especificou a forma e conteúdo da declaração de nascimento, também chamada de declaração de nascido vivo, quais os tipos de intercorrências de parto e anotações a respeito do desenvolvimento do neonato necessitariam constar. Trata-se, mais uma vez, de assunto a ser regulamentado por órgãos competentes, o que gerou críticas pela doutrina.

\footnotetext{
É necessária uma uniformização que contenha os dados mínimos. Uma padronização permitirá também uso dos dados para fins de enquetes epidemiológicas, planejamento de saúde e, sobretudo, para possibilitar continuidade dos cuidados neonatais através da infância (CURY, 2006, p. 64).
}

Não obstante as observações doutrinárias, reconhece-se a existência de iniciativas por parte do Ministério da Saúde para organizar a confecção das declarações padronizadas desde meados da década de noventa.

\footnotetext{
As Declarações de Nascido Vivo (DN) são impressas pelo Ministério da Saúde, por intermédio do Centro Nacional de Epidemiologia (Cenepi) da Fundação Nacional de Saúde (FUNASA), e distribuídas gratuitamente às secretarias estaduais de saúde, que as repassam aos estabelecimentos de saúde e cartórios (MINISTÉRIO DA SAÚDE. Disponível em: http://portal.saude.gov.br/portal/arquivos/pdf/declaracao_nasc_vivo. pdf).
}

Trata-se a declaração de um documento indispensável para o registro do nascimento em cartório. Esta obrigatoriedade veio a suprir uma falha de procedimento que possibilitava a popular adoção à Brasileira, em que uma mulher poderia registrar uma criança em um cartório como se sua fosse, conduta esta reprimida pelo Código Penal no artigo 242.

Com a declaração, o pai, a mãe, o parente mais próximo ou em último caso o administrador do hospital, médico, parteira ou outro que possua a guarda, deve fazer o registro em até quinze dias, prazo que é automaticamente dilatado quando a distância do local do nascimento ou residência dos pais até o Cartório for superior a trinta quilômetros.

Quando a declaração for levada a cartório fora do prazo, o cartório poderá diligenciar providências para averiguar a veracidade dos fatos narrados na declaração. Sem a declaração, 
só é possível lavrar assento de nascimento mediante ordem judicial obtida por meio de Ação de Suprimento de Assento dirigida ao Juiz competente.

Se o médico não emitir e estabelecimento hospitalar não fiscalizar, os dois podem ser processados pelo crime do artigo 228:

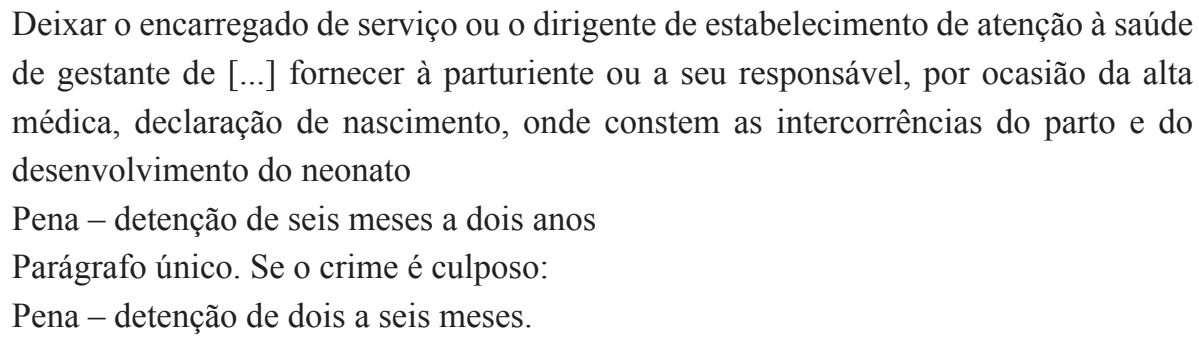

Trata-se da segunda parte do dispositivo já mencionado nos comentários do inciso primeiro do artigo décimo, motivo pelo qual outros comentários são dispensáveis.

Por fim, o inciso quinto do artigo décimo determina a manutenção em alojamento conjunto da mãe e da criança, medida de grande importância por proporcionar a aproximação dos dois, estimular a amamentação e minimizar o risco de trocas de criança.

Apesar das famigeradas dificuldades estruturais na saúde encontradas em diferentes localidades dentro do país, sabe-se que alguns municípios conseguem proporcionar este tipo de atendimento a ponto de a mãe sair da sala de parto com seu filho e ir diretamente para o alojamento, procedimento só interrompido ou postergado quando há comprometimento da saúde do recém-nascido ou da mãe.

Este inciso quinto é único que não encontra respaldo nos artigos 228 e 229 do ECA, que transforma em crimes, como já visto, a não observação dos cuidados atinentes aos outros incisos do artigo décimo, motivo pelo qual, pode-se até falsamente inferir que o bem tutelado pelo inciso quinto não careceria de tanta importância como os demais.

\section{CONCLUSÃO}

Como se apreende do exposto até então, o princípio da proteção integral trouxe uma série de desdobramentos até hoje inexplorados, haja vista a dinâmica das relações humanas e novos significados agregados ao teor do enunciado normativo.

Como averiguado, a saúde surge como um desses desdobramentos e é significante- 
mente influenciada pela doutrina do Direito da Criança e do Adolescente no que tange os novos papeis assumidos pelos infantes e pelas novas atribuições atribuídas ao Sistema de Saúde.

Dentre as atribuições, estudou-se dispositivos da lei 8.069/90 que garantem, por meio do atendimento à gestante e a mãe, a efetivação do Direito Social da Saúde.

Entretanto, é importante frisar que, não obstante o esforço desempenhado, trata-se de tema deveras complexo para ser esgotado com este estudo. Frequentemente realizam-se congressos, debates e seminários visando discutir os melhore meios de se buscar o atendimento ao ser humano durante este período que inspira tantos cuidados

Ademais, percebe-se que, apesar dos importantes passados conquistados pela legislação, ainda há muito que se conquistar em termos de efetividade. É necessário que o Poder Público assuma cada vez mais um compromisso com a população e não com o eleitorado e que a população se transforme, aos poucos, um conjunto político e consciente.

\section{REFERÊNCIAS}

BRASIL. Ministério da Saúde. Manual de instruções para o preenchimento da declaração de nascido vivo. Disponível em: < http://portal.saude.gov.br/portal/arquivos/pdf/declaracao_nasc_ vivo.pdf $>$. Acesso em: 6 fev. 2010

. Pré-natal e puerpério: atenção qualificada e humanizada. Disponível em: $<$ http://bvsms.saude.gov.br/bvs/publicacoes/caderno5_saude_mulher.pdf $>$. Acesso em: 4 fev. 2010.

ABC do Sus: doutrinas e princípios. Disponível em: <www.geosc.ufsc.br/babcsus. pdf>. Acesso em: 3 fev. 2010.

BURÉGIO, Alessandra Morais da Cunha. O Estatuto da criança e de adolescente e a política de proteção integral. Disponível em: $<\mathrm{http} / /$ www.tjpe.jus.br/vepa_arq/artigos/OK\%20Psicologia\%20Alessandra\%20Buregio.doc $>$ Acesso em: 6 jan.2010.

CURY, Munir, Estatuto da criança e do adolescente: comentários jurídicos e sociais. São Paulo: Moderna, 2006.

CUSTÓDIO. André Viana. Teoria da proteção integral: pressupostos para a compreensão do direito da criança e do adolescente. Disponível em: $<$ http://online.unisc.br/seer/index.php/direito/article/viewFile/657/454>. Acesso em: 6 jan. 2010.

ECAMARA. Consulta tramitação das proposições. Disponível em: $<$ http://www.camara.gov. br/sileg/Prop_Detalhe.asp?id=351542>. Acesso em: 3 fev. 2010. 
FERREIRA, Fabiana Alves. Puerpério. Disponível em: $<$ http://www.aguaviva.mus.br/enfermateca/Artigos/Puerperio.htm>. Acesso em: 3 fev. 2010.

FRANCO, Alberto Silva. STOCO, Rui. Leis penais especiais e sua interpretação jurisprudencial. 7. ed. São Paulo: Revista dos Tribunais, 2001.

GRAVIDEZ. Wikipédia. Disponível em: < http://pt.wikipedia.org/wiki/Gravidez>. Acesso em: 20 jun. 2010.

IHERING, Rudolf Von. A luta pelo direito. São Paulo: Edipro, 2001.

NOGUEIRA, Paulo Lúcio. Estatuto da criança e do adolescente comentado. São Paulo: Saraiva, 1991.

RAMOS, Luciana de Souza. Direito à amamentação e convivência familiar: possibilidade de afeto e resignificação do cárcere. Disponível em: <http://www.cfemea.org.br/pdf/artigo_creches_presidios_femininos.pdf>.Acesso em: 5 fev. 2010.

ROCHA, Eduardo Gonçalves; PEREIRA, Julyana Faria. Descentralização participatica e a doutrina da proteção integral da criança e do adolescente. Disponível em: <http://www.proec. ufg.br/revista_ufg/infancia/P_descentraliza.html>. Acesso em: 6 jan. 2010.

SARAIVA, João Batista Costa. Adolescente em conflito com a lei: da indiferença à proteção integral. 3. ed. Porto Alegre: Livraria do Advogado, 2009.

SILVA, José Afonso da. Curso de direito constitucional positivo. 27. ed. São Paulo: Moderna, 2006.

SANTOS, José Heitor dos. Aleitamento Materno nos presídios femininos. Disponível em: $<$ http://www.pjpp.sp.gov.br/2004/artigos/10.pdf>. Acesso em: 5 fev. 2009.

STELLA, Roberta. Alimentação certa para a mulher que amamenta. Disponível em: $<\mathrm{http}: / /$ www.minhavida.com.br/conteudo/1594-Alimentacao-certa-para-a-mulher-que-amamenta. htm>. Acesso em: 5 fev. 2010. 